\title{
Tocilizumab in management of refractory juvenile idiopathic arthritis, 10 years of experience at tertiary university hospital
}

\author{
Mohammed A. Muzaffer ${ }^{1}$ and Abobakr A. Abdelgalil ${ }^{1,2^{*}}$ (D
}

\begin{abstract}
Background: Juvenile idiopathic arthritis (JIA) is the most prevalent pediatric rheumatic disorder. Progress in modalities of therapy improves the disease outcome. We aimed to determine the efficacy and safety of tocilizumab (TCZ) in the management of systemic (sJIA) and polyarticular ( $\mathrm{pJIA}$ ) in children who are resistant to conventional as well as other biological therapies. In this retrospective study, we selected JIA patients according to the International League of Association for Rheumatology (ILAR) criteria and were treated with TCZ. Response to TCZ was assessed using Juvenile Arthritis Disease Activity Score-10 (JADAS-10) and also outcomes were assessed according to the American College of Rheumatology (ACR) remission criteria. Safety of the drug was assessed by documenting possibly related adverse effects (AE). Statistical analysis using SPSS version 25 with statistical significance is considered if $p \leq 0.05$. We included $16 \mathrm{JIA}$ patients aged $\leq 18$ years but 2 of them were excluded as they developed severe reaction during the TCZ 1st dose, so finally, 14 patients were included.

Results: The median age of our patients was 12 years. Of these 14 patients, 9 (64.3\%) had sJlA and 5 (35.7\%) had pJIA. TCZ use led to significant improvement in the JADAS-10 from mean $22.4( \pm 7.9)$ when it was initially assessed and then $3,6,12$, and 24 months after TCZ initiation with means $5.7( \pm 3.9), 4.4( \pm 3.7), 3.5( \pm 3.1)$, and $2.7( \pm 2.2),(P$ $=0.001,0.001,0.005,0.012)$, respectively. Five patients exhibited TCZ possibly expected side effects. Neutropenia and infusion-related reactions were the most frequent $\mathrm{AE}$.
\end{abstract}

Conclusions: Tocilizumab seems to be generally effective and safe drug in the management of sJIA and pJIA especially in cases refractory to conventional as well as other biologic agents.

Keywords: JIA, Tocilizumab, Efficacy, Safety, Biological therapy, JADAS

\section{Background}

Juvenile idiopathic arthritis (JIA) is the most prevalent pediatric rheumatic disorder. It is characterized by chronic arthritis of unknown cause, persisting for at least six consecutive weeks and beginning before the age of 16 years [1]. JIA is divided into seven categories according to ILAR classification [2]. Two of these categories are systemic JIA (sJIA) and poly-articular

\footnotetext{
* Correspondence: bakrsree@gmail.com

This work is an original article and was performed at King Abdulaziz University Hospital, Jeddah, Saudi Arabia.

${ }^{1}$ Department of Pediatrics, King Abdulaziz University, Jeddah, Saudi Arabia

${ }^{2}$ Department of Pediatrics, Cairo University, Cairo, Egypt
}

JIA (pJIA) that exhibit joint destruction, treatment resistance, and poor prognosis [3].

To avoid these undesirable complications, treatment should be early, aggressive [4], and also multidisciplinary to achieve a better prognosis [5]. In addition to the supportive treatment of JIA [6], the usual initial treatment is the conventional therapy in the form of diseasemodifying anti-rheumatic drugs (DMARDs) and steroids [7]. Some patients exhibit no or minimal response after about 3-6 months of use of DMARDs which moreover show some annoying side effects and toxicities. Such patients are candidates for starting biological therapy [8]. Many biological agents seem to be effective in achieving

\section{Springer Open}

(c) The Author(s). 2021 Open Access This article is licensed under a Creative Commons Attribution 4.0 International License, which permits use, sharing, adaptation, distribution and reproduction in any medium or format, as long as you give appropriate credit to the original author(s) and the source, provide a link to the Creative Commons licence, and indicate if changes were made. The images or other third party material in this article are included in the article's Creative Commons licence, unless indicated otherwise in a credit line to the material. If material is not included in the article's Creative Commons licence and your intended use is not permitted by statutory regulation or exceeds the permitted use, you will need to obtain permission directly from the copyright holder. To view a copy of this licence, visit http://creativecommons.org/licenses/by/4.0/. 
minimal disease activity and improvement of long-term prognosis [9].

One of these biologic agents is tocilizumab (TCZ) which is a humanized, monoclonal anti-IL6 antibody which binds to IL-6 receptors so impeding the action of IL-6 whose level increases in sera of JIA patients [10]. IL-6 promotes an inflammatory storm, as it induces the production of acute-phase reactants, promotes differentiation of B cells and $\mathrm{T}$ cells, inhibits regulatory $\mathrm{T}$ cells, and increases activation of osteoclasts [11].

TCZ has been approved by Food and Drug Administration (FDA) and European Medicines Agency (EMA) for both sIIA and pJIA pediatric patients above 2 years of age [12]. TCZ is reported as an efficient drug that reduces active manifestations in JIA patients and improves their life quality [13].

Although some adverse effects of TCZ were reported like hypersensitivity reaction [14], neutropenia, and increased liver transaminases, it seems to be a relatively safe drug [11].

So far, available data regarding the use of TCZ in the management of JIA in children are still limited especially in the Middle East [15], so our intention was to record our experience regarding TCZ benefits and possible adverse events in the management of both sJIA and pJIA.

\section{Methods}

This is a retrospective cross-sectional study conducted at a tertiary university hospital. We reviewed the medical files of all patients diagnosed as JIA (sJIA and pJIA) who were followed up at our pediatric rheumatology clinic and had been treated with TCZ at day care unit between 2011 and 2020. JIA patients were classified according to standards of the International League of Associations for Rheumatology (ILAR) [2].

All patients were exposed to detailed medical history, examination (included ophthalmological examination), and investigations that included CBC, CRP, ESR ALT, AST, lipid profile, BUN, creatinine, ferritin, rheumatoid factor (RF), anti-cyclic citrullinated peptide (anti-CCP), and anti-nuclear antibody (ANA) (in addition to the screening of all patients for tuberculosis by chest X-ray and tuberculin test).

The TCZ was given via intravenous infusion over $2 \mathrm{~h}$ : $12 \mathrm{mg} / \mathrm{kg}$ once every 2 weeks for sJIA patients and 10 $\mathrm{mg} / \mathrm{kg}$ every 4 weeks for pJIA patients and for both 8 $\mathrm{mg} / \mathrm{kg}$ if body weight is $\geq 30 \mathrm{~kg}$. TCZ was used for patients who had revealed no or inadequate response to previous medications namely DMARDs, corticosteroids, and other biological therapies.

Response to TCZ was assessed by using Juvenile Arthritis Disease Activity Score-10 (JADAS-10) before starting TCZ therapy and then 3 months, 6 months, 12 months, and 24 months after its use. The JADAS-10 is calculated by evaluating the 4 subsequent parameters (1) global evaluation of disease activity by the attending physician (by visual analog scale (VAS) where $0=$ no activity and $10=$ maximum activity); (2) parent/child assessment of well-being also assessed by VAS where $0=$ very well while $10=$ very poor; (3) active joints number $(0-10)$; and (4) ESR $(0-10)(\operatorname{ESR}(\mathrm{mm} / \mathrm{h})-20) / 10)$ so total score 0-40 [16].

Cutoff values of disease activity were classified into 4 classes: inactive, low disease activity, moderate and high disease activity if the score is $\leq 1,1.1-3.8,3.9-10.5$, and $>10.5$, respectively [17]. Those with inactive or low disease activity were considered as responders [18]. In sJIA, it can be assumed that presence of active systemic manifestations would be included in global assessment of both physician and patient/parent [19]. Moreover, patients with clinically inactive disease were classified according to ACR criteria (no arthritis, no uveitis, no systemic manifestations, normal ESR and CRP, best physician's judgment, and $\leq 15 \mathrm{~min}$ duration of morning stiffness) [20].

Safety of the drug was assessed by documenting possible side effects like drug reaction, infections, neutropenia (absolute neutrophil count (ANC) $<1.5 \times 10^{9} \mathrm{~L}$; mild if ANC is 1.0 to $1.5 \times 109 \mathrm{~L}$, moderate if 0.5 to 1.0 $\times 109 \mathrm{~L}$, and severe if it is less than $0.5 \times 10^{9} \mathrm{~L}$ ) [21], increased liver transaminases and also macrophage activation syndrome (MAS) which was diagnosed according to 2016 criteria [22]. A side effect was assigned to TCZ if this side effect had occurred at time of use of TCZ or within 3 months after stoppage.

This retrospective study was approved by Research Ethics Committee of our Institutional Review Board (Ref. number 481-20). The research was conducted in compliance with the values of the Helsinki Declaration.

\section{Statistical analysis}

Data were analyzed using the statistical package for the Social Sciences (SPSS) version 25 (IBM Corp., Armonk, NY, USA). Data were represented using mean, standard deviation, minimum and maximum in quantitative data, and using count and percentage for categorical data. Quantitative variables were compared using the nonparametric Kruskal-Wallis and Mann-Whitney tests. Serial measurements within each patient were compared using the non-parametric Wilcoxon signed rank test. Chi-square $\left(x^{2}\right)$ test was used to compare categorical data. Exact test was used instead when the expected frequency is less than 5 and $p$ value $\leq 0.05$ was considered statistically significant.

\section{Results}

The present study included 16 JIA pediatric patients aged $\leq 18$ years who had been treated by TCZ but 2 of 
them were excluded as they developed severe reaction during the 1st dose, so finally, 14 patients were included. Of these 14 patients, 9 (64.3\%) had systemic JIA and 5 (35.7\%) had polyarticular JIA. The median age of our patients was 12 years (the youngest was 6 years, and the oldest was 18 years). A Saudi Arabian nationality was the most prominent nationality (35.7\%). There was slight female gender predominance (57.1\%). The mean age of diagnosis of JIA was $7.6 \pm 3.4$ years. The mean duration of the disease was $5.2 \pm 2.7$ years and the mean disease duration before initiation of TCZ was $2.2 \pm 1.7$ years while the mean duration of TCZ use is defined as the time following TCZ initiation to the last dose of TCZ or to the time of writing this manuscript was $1.7 \pm 1.2$ years. Table 1 summarizes patients' baseline characteristics.

Regarding clinical manifestations at onset of the disease, none of the patients exhibited history of a concomitant illness. None had TB. All patients had arthritis $(100 \%)$ with median number of active joints at diagnosis is $8(1-21)$. All sJIA patients had fever while none of pJIA patients exhibited fever at onset of the disease $(P \leq$ $0.001)$. None of our patients had uveitis. Clinical features are summarized in Table 1.

Regarding laboratory analyses, there was statistically significant leukocytosis and anemia in sJIA rather than pJIA patients $(P=0.04)$. Also statistically significant, sIIA patients showed higher CRP and ferritin levels $(P=$ 0.02 ). Most of the patients had negative rheumatoid factor (RF) and anticyclic citrullinated peptide (anti-CCP) $(85.7$ and $78.6 \%)$ respectively as shown in Table 2.

Prior to the use of TCZ, all of the patients had received corticosteroids and methotrexate. Additionally, majority of the patients (71.4\%) had received other biological DMARDs; the most commonly used one was adalimumab (57.1\%). Only 5 (35.7\%) of the patients had received more than one biologic agents before starting TCZ. Medications used before TCZ are summarized in Table 1.

In order to assess TCZ efficacy, JADAS-10 was used. The mean value before initiation of TCZ was 22.4 ( \pm 7.9). We noticed that use of TCZ led to a statistically significant decrease in the score when was assessed 3, 6, 12 , and 24 months after TCZ initiation with means 5.7 ( \pm 3.9), $4.4( \pm 3.7), 3.5( \pm 3.1)$, and $2.7( \pm 2.2)(P=0.001$, $0.001,0.005,0.012)$, respectively, as in Fig. 1 which shows decreasing JADAS-10 score during follow-up period.

According to the last score measured, majority of the patients (71.4\%) were considered as responders; either had an inactive disease $(42.9 \%)$ or low disease activity (LDA) (28.6\%). Non-responders (28.6\%) patients exhibited moderate disease activity while none of the patients had high disease activity. Outcome was assessed
Table 1 Patients' baseline and clinical characteristics and medications used before TCZ

\begin{tabular}{|c|c|}
\hline \multicolumn{2}{|l|}{ Patients' baseline characteristics } \\
\hline Age, year mean (SD), median & $\begin{array}{l}12.7(3.7), 12(6- \\
18)\end{array}$ \\
\hline Female, n (\%) & $8(57.1)$ \\
\hline \multicolumn{2}{|l|}{ Nationality, n (\%) } \\
\hline Saudi & $5(35.7)$ \\
\hline Yemeni & $4(28.6)$ \\
\hline Bangladeshi & $2(14.3)$ \\
\hline Syrian & $1(7.1)$ \\
\hline Palestinian & $1(7.1)$ \\
\hline Pakistani & $1(7.1)$ \\
\hline Age at diagnosis, year mean (SD), median & $\begin{array}{l}7.6(3.4), 8.2(0.5- \\
13)\end{array}$ \\
\hline \multicolumn{2}{|l|}{ JIA subtype, n (\%) } \\
\hline Poly JIA & $5(35.7)$ \\
\hline SOJIA & $9(64.3)$ \\
\hline Disease duration, year mean (SD), median & $\begin{array}{l}5.2(2.7), 5.8(0.4- \\
9.5)\end{array}$ \\
\hline Duration of TCZ use, year mean (SD), median & $\begin{array}{l}1.7(1.2), 1.3(0.3- \\
4)\end{array}$ \\
\hline $\begin{array}{l}\text { Disease duration at TCZ use, yr. mean (SD), } \\
\text { median }\end{array}$ & $2.2(1.7), 2(0.1-5)$ \\
\hline joints involved (n) at onset of disease & $7.9(5.2), 8(1-21)$ \\
\hline \multicolumn{2}{|l|}{ Clinical manifestations $\mathrm{n}(\%)$} \\
\hline Arthritis & $14(100)$ \\
\hline Fever & $9(64.3)$ \\
\hline Rash & $5(35.7)$ \\
\hline LNs & $1(7.1)$ \\
\hline HSM & $2(14.3)$ \\
\hline Serositis & $0(0.0)$ \\
\hline Uveitis & $0(0.0)$ \\
\hline \multicolumn{2}{|l|}{ Pre TCZ medications n (\%) } \\
\hline Methotrexate & $14(100)$ \\
\hline Corticosteroids & $14(100)$ \\
\hline Intravenous Immunoglobulin (IVIG) & $3(21.4)$ \\
\hline Etanercept & $7(50)$ \\
\hline Adalimumab & $8(57.1)$ \\
\hline NSAIDs & $12(85.7)$ \\
\hline Mycophenolate mofetil (MMF) & $2(14.3)$ \\
\hline Cyclosporine & $1(7.1)$ \\
\hline Abatacept & $1(7.1)$ \\
\hline
\end{tabular}

Abbreviations: $S D$ standard deviation, Poly poly-articular, sJIA systemic, JIA juvenile idiopathic arthritis, LNs lymphadenopathy, HSM hepatosplenomegaly, TCZ tocilizumab, NSAIDs non-steroidal anti-inflammatory drugs

according to ACR criteria, where majority of the patients (64.3\%) had achieved remission after TCZ use; either with complete discontinuation of medications (28.6\%) or 
Table 2 Laboratory results of poly JIA and SOJIA

\begin{tabular}{|c|c|c|c|c|}
\hline Parameter & $\begin{array}{l}\text { Poly JIA } \\
\text { Mean }( \pm \text { SD) }\end{array}$ & $\begin{array}{l}\text { SOJIA } \\
\text { Mean ( } \pm \text { SD) }\end{array}$ & Reference range & $P$ value \\
\hline \multicolumn{5}{|l|}{$\overline{C B C}$} \\
\hline Hemoglobin, gm/dl & $11.3(1.9)$ & $9.3(1.07)$ & $9.6-15.6$ & 0.042 \\
\hline 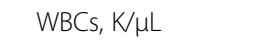 & $10.3(4.5)$ & $18.7(6.9)$ & $5.5-17.5$ & 0.042 \\
\hline 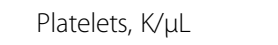 & $487.8(196.3)$ & 529 (171.6) & $150-450$ & 0.797 \\
\hline $\mathrm{ESR}, \mathrm{mm} / \mathrm{h}$ & $45(53.9)$ & $65.7(41.8)$ & $0-10$ & 0.364 \\
\hline $\mathrm{CRP}, \mathrm{mg} / \mathrm{L}$ & $26.04(40.6)$ & $120.5(59.8)$ & $0-3$ & 0.019 \\
\hline \multicolumn{5}{|l|}{ Liver enzymes } \\
\hline AST, U/L & $16(2.4)$ & $23.1(11.7)$ & $15-37$ & 0.240 \\
\hline$A L T, U / L$ & $24.2(12.2)$ & $31.1(17.9)$ & $12-78$ & 0.364 \\
\hline \multicolumn{5}{|l|}{ Renal functions } \\
\hline Urea, mmol/L & $3.9(1.1)$ & $3.6(1.4)$ & $2.5-6.4$ & 0.699 \\
\hline Creatinine, $\mu \mathrm{mol} / \mathrm{L}$ & $42.4(12.7)$ & $32.1(9.4)$ & 53-115 & 0.240 \\
\hline Ferritin, ng/ml & $17(13.8)$ & $1814.4(3417.9)$ & $30-400$ & 0.024 \\
\hline RF positive n. (\%) & $2(14.3 \%)$ & $0(0.0)$ & $<20$ & 0.110 \\
\hline A-CCP positive $n .(\%)$ & $2(14.3 \%)$ & $0(0.0)$ & $<20$ & 0.110 \\
\hline ANA positive $n .(\%)$ & $3(21.4 \%)$ & $4(28.6 \%)$ & $<1: 40$ & 1 \\
\hline
\end{tabular}

Abbreviations: $C B C$ complete blood count, WBC white blood cell, ESR erythrocyte sedimentation rate, CRP C-reactive protein, $A S T$ aspartate transaminase, $A L T$ alanine transaminase, $R F$ rheumatoid factor, $A-C C P$ anticyclic citrullinated peptide, $A N A$ antinuclear antibody

remission on medications (35.7\%). Outcome of the disease according to the last JADAS-10 score and ACR criteria for remission was illustrated in Table 3.

We found no statistically significant correlations between disease duration before the initiation of tocilizumab, age of the patient, baseline inflammatory markers levels, medications used prior to TCZ, and the clinical outcome of TCZ treatment. The only statistically significant correlation to remission outcome was attributed to improved JADAS score parameters through the follow-up period $(P=0.004)$.

In all, 2 patients developed severe reaction during the 1 st dose so they couldn't continue and were excluded from the study. Three (5 events) ( 2 sJIA and one pJIA) (21.4\%) patients developed neutropenia during the TCZ course. This neutropenia was mild to moderate and resolved within 2-3 weeks. None of the patients experienced TCZ possibly related infections, elevated

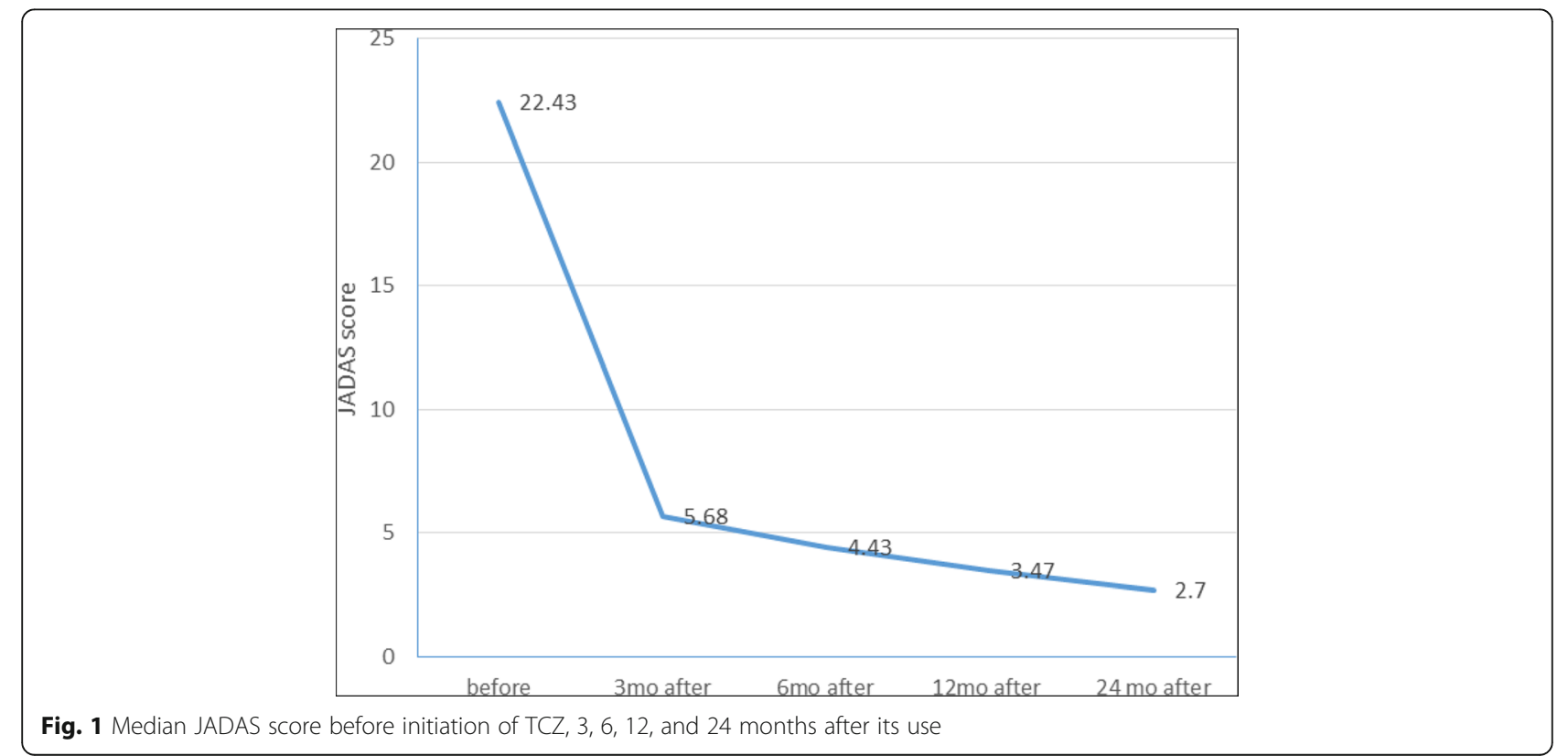


Table 3 Clinical activity and outcomes of the study group

\begin{tabular}{lll}
\hline Outcome & Activity (according to last visit) & $\mathbf{n}(\%)$ \\
\hline Disease activity (last JADAS-10 score) & Moderate disease activity (MDA) & $4(28.6)$ \\
& Low disease activity (LDA) & $4(28.6)$ \\
Responders & Inactive & 10(72.9) \\
Non-responders & Inactive and LDA & $4(28.6)$ \\
Outcome (ACR criteria) & MDA & $4(28.6)$ \\
& Remission & $5(35.7)$ \\
& Remission on medication & $5(35.7)$ \\
\hline
\end{tabular}

Abbreviations: JADAS Juvenile Arthritis Disease Activity Score, ACR American College of Rheumatology

transaminases, macrophage activation syndrome (MAS), hyperlipidemia, malignancy, autoimmune diseases, or deaths. No significant correlation had been found between the duration of TCZ use and incidence of the adverse events $(\mathrm{AE})$.

\section{Discussion}

Over the last 2 decades, newly emerged cytokinetargeted biologic agents have revolutionized the management and outcome of JIA. One of these biologics is TCZ which has been approved for the management of sJIA and pJIA. Nevertheless, few reports especially from Middle East have described the efficacy and safety of TCZ in the treatment of JIA in children $[9,15]$. This study adds to the previous knowledge by shedding light on the use of TCZ in the treatment of sJIA and pJIA children who exhibited resistance to conventional and other biological therapies.

In the current study, we found that TCZ use has led to considerable improvement in the JADAS-10 score during 24 months follow-up. This score was significantly improved when it was assessed 3, 6, 12, and 24 months after TCZ initiation $(P=0.001$, $0.001,0.005$, and 0.012), respectively. Additionally, according to the last score measured (24 months), majority of our patients (71.5\%) were considered as responders; either had an inactive disease $(42.9 \%)$ or LDA (28.6\%). Moreover, the outcome assessed according to ACR criteria showed that majority of our patients (64.3\%) had achieved remission after TCZ use; either with complete discontinuation of medications $(28.6 \%)$ or remission on medications (35.7\%). These findings of the current study were consistent with those of previous studies. The randomized trial done by De Benedetti et al. demonstrated considerable improvement in articular and systemic manifestations of sJIA children who were treated with TCZ compared to the placebo group achieving JIA ACR 30 response by $85 \%(P \leq 0.01)$ at the 3rd month after TCZ initiation. Furthermore, at the 12th month, 80 and $59 \%$ of the patients had achieved JIA
ACR 70 and 90\%, respectively. Moreover, 32\% had clinically inactive disease and $48 \%$ had no active arthritis [23]. Another randomized trial conducted by Brunner et al, 2015 revealed TCZ efficacy in the management of pJIA children who had achieved ACR 70 and 90 responses by 64.6 and $45.1 \%$, respectively [24]. Recently, in 2020, an extension of the phase 3 trial by Brunner et al. supported the efficacy of TCZ in pJIA patients with longer follow-up period. At about 24 months of TCZ use, JIA ACR 50, 70, and 90 responses were achieved by 80.3, 77.1, and $59.6 \%$, respectively. Additionally, the median JADAS-71 score decreased from 3.6 at week 40 to 0.7 at the 24 months [25].

Interestingly, the effectiveness of TCZ in both sJIA and pJIA has been exemplified in other reports using variable scores $[8,10,11,13,26,27]$.

Horneff et al. revealed that earlier initiation of TCZ in sJIA was associated with better JADAS-10 score but there was no relation between disease duration and achieving ACR remission criteria [26]. Our study did not find a statistically significant correlation between the clinical outcome of TCZ treatment and pre-TCZ disease duration, baseline clinical features, inflammatory marker levels, or TCZ pre-medications, similarly as observed by Roszkiewicz et al. [11].

The overall incidence of adverse events (AE) has been evaluated in several studies and it was variable. This may be attributed to the variability of study designs and an indication of TCZ use (i.e., sJIA or pJIA) [8]. The safety of TCZ in this JIA cohort was mostly consistent with the identified safety profile.

Neutropenia is one of the most frequently reported $\mathrm{AE}$ in previous reports $[8,11,23,25,28]$ who have reported neutropenia in both sJIA and pJIA in variable frequencies $(18 \%, 50 \%, 10 \%, 17 \%, 37.2 \%)$, respectively. In line with the results from previous studies, we reported neutropenia in 3 (5 events) (2 sJIA and one pJIA) (21.4\%) patients during the TCZ course. This neutropenia was mild to moderate and resolved within $2-3$ weeks. None of these patients experienced possibly related infections 
during periods of neutropenia which corroborates with previous reports $[24,29]$.

In reviewing the literature, TCZ infusion-related reaction incidence was variable $(0-30 \%)$ [8, 11, 15, 26-28]. In our study, 2 (out of 16) (12.5\%) patients developed severe reaction during the 1st infusion so they could not continue and were excluded from the study.

As mentioned in several studies, infection is the most frequently revealed side effect of TCZ use [13, 23, 25]. Contrary to expectations, none of our patients developed TCZ possibly related significant infections. Such considerable difference may be attributed to retrospective analysis and possible missing data about minor infections which resolved spontaneously and did not affect the next infusion.

None of our patients experienced TCZ possibly related elevated transaminases, macrophage activation syndrome (MAS), hyperlipidemia, malignancy, autoimmune diseases, or deaths, which is consistent with previous reports $[8,13,15,27]$.

There was no meaningful association between the longer period of TCZ use and incidence of the AE which is in agreement with Opoka-Winiarska et al. findings [10].

Several limitations to this study need to be acknowledged. The limited number of patients, the singlecentered, and the retrospective nature of the study. However, most of data concerning JIA variables and principals were prospectively available.

\section{Conclusion}

Tocilizumab safety has been verified in the management of sIIA and pJIA patients who are refractory to conventional as well as other biologic agents and it was consistent with the known safety profile with minimal, tolerable, and transient side effects.

\footnotetext{
Abbreviations

JIA: Juvenile idiopathic arthritis; TCZ: Tocilizumab; sJIA: Systemic juvenile idiopathic arthritis; pJIA: Polyarticular juvenile idiopathic arthritis; ILAR: International League of Association for Rheumatology; JADAS10: Juvenile Arthritis Disease Activity Score-10; ACR: American College of Rheumatology; AE: Adverse effects; DMARDs: Disease-modifying antirheumatic drugs; FDA: Food and Drug Administration; EMA: European Medicines Agency; CBC: Complete blood count; WBC: White blood cell; ESR: Erythrocyte sedimentation rate; CRP: C-reactive protein; AST: Aspartate transaminase; ALT: Alanine transaminase; RF: Rheumatoid factor; A-CCP: Anticyclic citrullinated peptide; ANA: Antinuclear antibody; NSAIDs: Non-steroidal anti-inflammatory drugs; VAS: Visual analog scale; ANC: Absolute neutrophil count; TB: Tuberculosis; LDA: Low disease activity; MAS: Macrophage activation syndrome
}

\section{Acknowledgements}

Not applicable

\section{Authors' contributions}

MM: study concept/design and critical revision of the article. AA: study concept/design, data collection \& interpretation, writing the article, and reviewing the manuscript. All authors read and approved the final manuscript.

\section{Funding}

There was no funding for this report.

Availability of data and materials

Available upon request.

\section{Declarations}

\section{Ethics approval and consent to participate}

The study was approved by King Abdulaziz University institutional review board (Ref. number 481-20). Consent is not applicable (retrospective study)

\section{Consent for publication}

Not applicable

\section{Competing interests}

The authors declare that they have no competing interests.

Received: 8 April 2021 Accepted: 26 May 2021

Published online: 01 July 2021

\section{References}

1. Giani T, Madera A, Cimaz R (2020) Association of juvenile idiopathic arthritis and morphea: a case series. Clin Rheumatol 39:1341-1345. https://doi.org/1 0.1007/s10067-019-04850-5

2. Petty RE, Southwood TR, Manners P, Baum J, Glass DN, Goldenberg J, He X, Maldonado-Cocco J, Orozco-Alcala J, Prieur AM, Suarez-Almazor ME, Woo P International League of Associations for Rheumatology (2004) International League of Associations for Rheumatology classification of juvenile idiopathic arthritis: second revision, Edmonton, 2001. J Rheumatol 31:390-392

3. Viswanathan V, Murray KJ (2016) Management of children with juvenile idiopathic arthritis. Indian J Pediatr 83:63-70. https://doi.org/10.1007/s12098015-1966-1

4. Kasapçopur Ö, Barut K (2015) Treatment in juvenile rheumatoid arthritis and new treatment options. Turk Pediatri Ars 50:1-10

5. Seaman SC, Hong S, Dlouhy BJ, Menezes AH (2020) Current management of juvenile idiopathic arthritis affecting the craniovertebral junction. Childs Nerv Syst 36:1529-1538

6. Dağdeviren-Çakır A, Arvas A, Barut K, Gür E, Kasapçopur Ö (2016) Serum vitamin $D$ levels during activation and remission periods of patients with juvenile idiopathic arthritis and familial Mediterranean fever. Turk J Pediatr 58:125-131

7. Turnier JL, Brunner HI (2016) Tocilizumab for treating juvenile idiopathic arthritis. Expert Opin Biol Ther 16:559-566

8. Grönlund MM, Remes-Pakarinen T, Kröger L, Markula-Patjas K, Backström M, Putto-Laurila A, Aalto K, Vähäsalo P (2020) Efficacy and safety of tocilizumab in a real-life observational cohort of patients with polyarticular juvenile idiopathic arthritis. Rheumatology (Oxford) 59:732-741. https://doi.org/10.1 093/rheumatology/kez291

9. Mehta J, Beukelman T (2017) Biologic agents in the treatment of childhoodonset rheumatic disease. J Pediatr 189:31-39. https://doi.org/10.1016/j. jpeds.2017.06.041

10. Opoka-Winiarska V, Żuber Z, Alexeeva E, Chasnyk V, Nikishina I, Dębowska G, Smolewska E (2018) Long-term, interventional, open-label extension study evaluating the safety of tocilizumab treatment in patients with polyarticularcourse juvenile idiopathic arthritis from Poland and Russia who completed the global, international CHERISH trial. Clin Rheumatol 37:1807-1816. https://doi.org/10.1007/s10067-018-4071-9

11. Roszkiewicz J, Orczyk K, Smolewska E (2018) Tocilizumab in the treatment of systemic-onset juvenile idiopathic arthritis - single-centre experience. Reumatologia 56:279-284. https://doi.org/10.5114/reum.2018.79497

12. Ruiz-Medrano J, Díaz-Valle D, Cuiña R, Gegúndez JA, Chhablani J, Majumder PD, Gutierrez-Bonet R (2018) The role of tocilizumab in the treatment of inflammatory diseases of the eye and orbit: a useful alternative. J Fr Ophtalmol 41:759-766. https://doi.org/10.1016/j.jfo.2018.02.006

13. Yazılıtaş F, Özdel S, Şimşek D, Aydoğ Ö, Çakıcı EK, Can GG, Güngör T, Bülbül M (2019) Tocilizumab for juvenile idiopathic arthritis: a single-center case series. Sao Paulo Med J 137:517-522. https://doi.org/10.1590/1516-3180.201 8.0489220719

14. Yasuoka R, Iwata N, Abe N, Kohagura T, Nakaseko H, Shimizu M, Kawabe S (2019) Risk factors for hypersensitivity reactions to tocilizumab introduction 
in systemic juvenile idiopathic arthritis. Mod Rheumatol 29:324-327. https:// doi.org/10.1080/14397595.2018.1457490

15. Al-Mayouf SM, Alenazi A, AlJasser H (2016) Biologic agents therapy for Saudi children with rheumatic diseases: indications and safety. Int J Rheum Dis 19: 600-605. https://doi.org/10.1111/1756-185X.12365

16. Consolaro A, Bracciolini G, Ruperto N, Pistorio A, Magni-Manzoni S, Malattia C, Pederzoli S, Davì S, Martini A, Ravelli A (2012) Paediatric Rheumatology International Trials Organization. Remission, minimal disease activity, and acceptable symptom state in juvenile idiopathic arthritis: defining criteria based on the juvenile arthritis disease activity score. Arthritis Rheum 64:2366-2374. https://doi. org/10.1002/art.34373

17. Consolaro A, Ruperto N, Bracciolini G, Frisina A, Gallo MC, Pistorio A, Verazza S, Negro G, Gerloni V, Goldenstein-Schainberg C, Sztajnbok F, Wulffraat NM, Martini A, Ravelli A, Paediatric Rheumatology International Trials Organization (PRINTO) (2014) Defining criteria for high disease activity in juvenile idiopathic arthritis based on the juvenile arthritis disease activity score. Ann Rheum Dis 73:1380-1383 TCZ ref vancouver.docx

18. Demirkaya E, Consolaro A, Sonmez HE, Giancane G, Simsek D, Ravelli A (2016) Current research in outcome measures for pediatric rheumatic and autoinflammatory diseases. Curr Rheumatol Rep 18:8

19. Klotsche J, Raab A, Niewerth M, Sengler C, Ganser G, Kallinich T, Niehues T, Hufnagel M, Thon A, Hospach T, Horneff G, Minden K (2016) Outcome and trends in treatment of systemic juvenile idiopathic arthritis in the german national pediatric rheumatologic database, 2000-2013. Arthritis Rheumatol 68:3023-3034

20. Wallace CA, Giannini EH, Huang B, Itert L, Ruperto N, Childhood Arthritis Rheumatology Research Alliance, Pediatric Rheumatology Collaborative Study Group, Paediatric Rheumatology International Trials Organisation (2011) American College of Rheumatology provisional criteria for defining clinical inactive disease in select categories of juvenile idiopathic arthritis. Arthritis Care Res 63:929-936

21. Walkovich K, Boxer LA (2013) How to approach neutropenia in childhood. Pediatr Rev 34:173-184. https://doi.org/10.1542/pir.34-4-173

22. Ravelli A, Minoia F, Davì S, Horne A, Bovis F, Pistorio A, Aricò M et al (2016) 2016 Classification Criteria for Macrophage Activation Syndrome Complicating Systemic Juvenile Idiopathic Arthritis: a European League Against Rheumatism/American College of Rheumatology/Paediatric Rheumatology International Trials Organisation Collaborative Initiative. Arthritis Rheumatol 68:566-576. https://doi.org/10.1002/art.39332

23. De Benedetti F, Brunner HI, Ruperto N, Kenwright A, Wright S, Calvo I, Cuttica $R$ et al (2012) Randomized trial of tocilizumab in systemic juvenile idiopathic arthritis. N Engl J Med 367:2385-2395. https://doi.org/10.1056/ NEJMoa1112802

24. Brunner HI, Ruperto N, Zuber Z, Keane C, Harari O, Kenwright A, Lu P et al (2015) Efficacy and safety of tocilizumab in patients with polyarticularcourse juvenile idiopathic arthritis: results from a phase 3, randomised, double-blind withdrawal trial. Ann Rheum Dis 74:1110-1117. https://doi. org/10.1136/annrheumdis-2014-205351

25. Brunner HI, Ruperto N, Zuber Z, Cuttica R, Keltsev V, Xavier RM, Burgos-Vargas R et al (2020) Efficacy and safety of tocilizumab for polyarticular-course juvenile idiopathic arthritis in the open-label 2year extension of a phase 3 trial. Arthritis Rheumatol. https://doi. org/10.1002/art.41528

26. Horneff G, Schulz AC, Klotsche J, Hospach A, Minden K, Foeldvari I, Trauzeddel R, Ganser G, Weller-Heinemann F, Haas JP (2017) Experience with etanercept, tocilizumab and interleukin-1 inhibitors in systemic onset juvenile idiopathic arthritis patients from the BIKER registry. Arthritis Res Ther 19:256. https://doi.org/10.1186/s13 075-017-1462-2

27. Demir S, Sönmez HE, Arslanoğlu-Aydın E, Özen S, Bilginer Y (2019) Tocilizumab treatment in juvenile idiopathic arthritis patients: a single center experience. Turk J Pediatr 61:180-185. https://doi.org/10.24953/ turkjped.2019.02.005

28. Klein A, Klotsche J, Hügle B, Minden K, Hospach A, WellerHeinemann F, Schwarz T et al (2020) Long-term surveillance of biologic therapies in systemic-onset juvenile idiopathic arthritis: data from the German BIKER registry. Rheumatology 59:2287-2298. https://doi.org/10.1093/rheumatology/kez577
29. Pardeo M, Wang J, Ruperto N, Alexeeva E, Chasnyk V, Schneider R, Horneff $\mathrm{G}$ et al (2019) Neutropenia during tocilizumab treatment is not associated with infection risk in systemic or polyarticular-course juvenile idiopathic arthritis. J Rheumatol 46:1117-1126. https://doi.org/10.3899/jrheum.180795

\section{Publisher's Note}

Springer Nature remains neutral with regard to jurisdictional claims in published maps and institutional affiliations.

\section{Submit your manuscript to a SpringerOpen ${ }^{\circ}$ journal and benefit from:}

- Convenient online submission

- Rigorous peer review

- Open access: articles freely available online

- High visibility within the field

- Retaining the copyright to your article

Submit your next manuscript at $\boldsymbol{\nabla}$ springeropen.com 